\title{
Short-term Outcomes of Elective 2-Stage Restorative Proctocolectomy for Ulcerative Colitis in Korea: Does Laparoscopy Have Benefits?
}

\author{
Jun Woo Bong ${ }^{1}$, Yong Sik Yoon², Jong Lyul Lee², Chan Wook Kim², In Ja Park², Seok-Byung Lim², \\ Chang Sik Yu², Jin Cheon Kim² \\ ${ }^{1}$ Division of Colorectal Surgery, Department of Surgery, Korea University Guro Hospital, Korea University College of Medicine, Seoul; \\ ${ }^{2}$ Division of Colon and Rectal Surgery, Department of Surgery, Asan Medical Center, University of Ulsan College of Medicine, Seoul, Korea
}

Purpose: This study aimed to compare the short-term outcomes of the open and laparoscopic approaches to 2-stage restorative proctocolectomy (RPC) for Korean patients with ulcerative colitis (UC).

Methods: We retrospectively analyzed the medical records of 73 patients with UC who underwent elective RPC between 2009 and 2016. Patient characteristics, operative details, and postoperative complications within 30 days were compared between the open and laparoscopic groups.

Results: There were 26 cases (36\%) in the laparoscopic group, which had a lower mean body mass index $(\mathrm{P}=0.025)$, faster mean time to recovery of bowel function $(P=0.004)$, less intraoperative blood loss $(P=0.004)$, and less pain on the first and seventh postoperative days $(\mathrm{P}=0.029$ and $\mathrm{P}=0.027$, respectively) compared to open group. There were no deaths, and the overall complication rate was $43.8 \%$. There was no between-group difference in the overall complication rate; however, postoperative ileus was more frequent in the open group $(27.7 \%$ vs. $7.7 \%, \mathrm{P}=0.043$ ). Current smoking (odds ratio $[\mathrm{OR}], 44.4 ; \mathrm{P}=0.003)$ and open surgery $(\mathrm{OR}, 5.4 ; \mathrm{P}=0.014)$ were the independent risk factors for postoperative complications after RPC.

Conclusion: Laparoscopic RPC was associated with acceptable morbidity and faster recovery than the open approach. The laparoscopic approach is a feasible and safe option for surgical treatment for UC in selective cases.

Keywords: Ulcerative colitis; Laparoscopy; Restorative proctocolectomy; Treatment outcomes

\section{INTRODUCTION}

Despite recent advancements in medical treatments, ulcerative colitis (UC) continues to have a relapsing-remitting clinical course, without significant predictors, and colectomy rate of about $30 \% 10$ years after diagnosis [1]. Prolonged disease increases the

Received: February 11, 2019 - Accepted: March 29, 2019

Correspondence to: Yong Sik Yoon, M.D.

Department of Surgery, Asan Medical Center, University of Ulsan College of Medicine, 88 Olympic-ro 43-gil, Songpa-gu, Seoul 05505, Korea

Tel: +82-2-3010-5318, Fax: +82-2-3010-6701, E-mail: yoonys@amc.seoul.kr ORCID: https://orcid.org/0000-0002-3196-8423

(C) 2020 The Korean Society of Coloproctology

This is an open-access article distributed under the terms of the Creative Commons Attribution NonCommercial License (https://creativecommons.org/licenses/by-nc/4.0) which permits unrestricted non-

commercial use, distribution, and reproduction in any medium, provided the original work is properly cited. risk of progression to colorectal cancer, with cumulative probabilities of $2 \%$ by 10 years, $8 \%$ by 20 years, and $18 \%$ by 30 years [2]. Restorative proctocolectomy (RPC) using ileal pouch-anal anastomosis (IPAA) was first introduced in 1978, and it is considered as standard treatment for refractory UC [3]. RPC has enhanced the quality of life among patients with UC by preventing the need for permanent ileostomy and maintaining intestinal continuity.

Previous studies had reported that the overall complication rates of open RPC were up to $30 \%-40 \%$ [4]. Recent studies showed acceptable outcomes of laparoscopic RPC compared to open RPC with less than 30\% [5, 6]. In Asia, there is a dearth of data on laparoscopic RPC for UC because of the low incidence of UC on the continent [6]. The incidence and prevalence of UC in Korea have been steadily increasing since the 1980s but are still low compared to Western countries [7]. However, as dietary habits of Asian countries gradually become westernized, the incidence of inflamma- 
tory bowel disease is continually increasing, and there is also a growing need to study and suggest a suitable treatment for UC patients in Asian society. Asan Medical Center manages the colorectal surgery patients in Korea, including those with inflammatory bowel disease, and laparoscopic surgery for UC has been gradually instituted since late the 2000s. With our accumulated experience and data related to laparoscopic RPC, we are now able to compare the short-term outcomes of the laparoscopic vs. open approaches to 2-staged RPC for Korean patients with UC.

\section{METHODS}

\section{Patients and data collection}

We retrospectively reviewed the data on surgical interventions for UC carried out between January 2009 and December 2016 at Asan Medical Center. From the 109 patients' records initially screened, we excluded 27 patients who underwent 3-stage RPC for severe colitis, 1 patient who underwent 1-stage RPC, and 8 patients who underwent emergency 2-stage RPC. We analyzed the remaining 73 cases, which comprised elective 2-stage RPCs.

We divided the cases into 2 groups - the open and laparoscopic groups-for comparisons of clinical variables and outcomes among UC patients. Recorded demographic and clinical variables were age at diagnosis, gender, body mass index (BMI), duration between diagnosis and surgery, American Society of Anesthesiologists (ASA) physical status classification, smoking history, history of previous abdominal surgery, preoperative medical treatments, indication for operation, preoperative hemoglobin level, preoperative albumin level, and preoperative transfusion requirement. Current smokers included patients who were tobacco smokers at the time of surgery and those who had quit within the previous 1 year. Patients who had quit more than 1 year before surgery were considered as ex-smokers, and the third category based on smoking history included patients who never smoked [5]. Intraoperative details included use of laparoscopy, operative time, anastomotic configuration, requirement for conversion, and estimated blood loss (EBL). Perioperative and postoperative outcomes included morbidity and mortality within 30 postoperative days, requirement for readmission or reoperation, length of hospital stay (days), time to recovery of bowel function, postoperative pain by numeric pain rating scale (NRS), and postoperative transfusion requirement. The Clavien-Dindo classification (CDC) was applied for the assessment of postoperative morbidity [8].

\section{Definitions}

We defined the medical intractability as a lack of response to at least 7 days of drug therapy or failure to withdraw steroid therapy. Preoperative UC medications were divided into 4 categories: steroids, biologics (infliximab, adalimumab, or certolizumab pegol), immunomodulators (azathioprine or 6-mercaptopurine), and anti-inflammatory agents (5-aminosalicylic acid or budesonide). As a definition for study purposes, steroid or anti-inflammatory use required the administration of a medication belonging to either respective drug category within the month before surgery. Biologic medication use was defined as the administration of at least one anti-tumor necrosis factor agent infusion of within the 3 months before surgery. Immunomodulator use was defined within 2 months before surgery [9]. Immunosuppressive medications included steroids, biologics, and immunomodulators but not anti-inflammatory agents.

Ileus was defined as the absence of bowel function by postoperative day 5 or the need for nasogastric tube insertion due to abdominal distension, nausea, or vomiting without evidence of mechanical bowel obstruction. The definition of postoperative small bowel obstruction was based on either imaging studies or operative intervention with findings consistent with mechanical small bowel obstruction after postoperative day 5 [10]. Septic complications included anastomotic leakage, abdominal abscess, and sepsis or septic shock resulting from anastomotic leakage or abdominal abscess formation.

\section{Operation and postoperative management}

All surgeries were performed by colorectal disease-specialized surgeons of Asan Medical Center with more than 5-year of experience. Surgical decisions and choice of laparoscopy vs. laparotomy were mainly based on the experience and preferences of the operating surgeon. Straight laparoscopic RPC generally consisted of 5 ports, including a periumbilical camera port and working ports for the left and right upper and lower quadrants. After adequate mobilization and vascular ligation of the terminal ileum, colon, and rectum, the distal rectum was transected using endoscopic linear staplers. A wound protector was placed through a 4to $8-\mathrm{cm}$ incision through the umbilicus or stoma site. After the bowel segment to be intervened upon was exteriorized, an ileal division and construction of a 10 - to $15-\mathrm{cm}$ J pouch were performed extracorporeally. When the pouch-anus anastomosis was completed, a diverting ileostomy was constructed on the right or left lower abdominal quadrant. A mucosectomy was generally indicated when a rectal malignancy or dysplasia was identified.

The same perioperative management was administered to both groups. In general, mechanical bowel preparation was used, and nasogastric tubes were not used. Patient-controlled analgesia combined with intravenous ketorolac was the preferred choice for postoperative pain management. Patients who experienced postoperative pain of NRS 4 or more received an additional intravenous opioid bolus (pethidine $25 \mathrm{mg}$ ) on request. We compared the mean number of doses of additional opioid administered during the hospital day between the 2 groups. Each patient was given sips of water on postoperative day 1 and encouraged to ambulate frequently. Incentive spirometry and pharmacologic thromboprophylaxis were also used. Liquid diets were offered to patients once stoma function was confirmed. Patients who could tolerate the liquid diet were offered solid food and started on oral analgesics. Discharge criteria included tolerance of meals without nausea or 
Volume 36, Number 1, 2020

vomiting, established bowel or stoma function, adequate pain control with oral analgesia, and independent ambulation.

\section{Statistical analysis}

Data were analyzed using IBM SPSS Statistics ver. 21.0 (IBM Co., Armonk, NY, USA). Discrete values, such as gender, operative indications, preoperative medical treatment, and readmission were compared using Pearson chi-square test or Fisher exact test. Student t-test was used to compare continuous values, such as BMI, operative time, duration of disease, and length of postoperative stay. Data are presented as means \pm standard deviation. Univariate and multivariate analyses were performed using the logistic regression model for risk factors of postoperative complications. The results were presented as an odds ratio (OR) and the 95\% confidence interval (CI). Variables with a P-value $\leq 0.1$ in the univariate analysis were included in the multivariate analysis. Additional multivariate analyses were performed with statistical signif- icance designated at $\mathrm{P}<0.05$. The Institutional Review Board (IRB) of our institute approved this study (approval number: S2017-0780-0001). The informed consent was waived by IRB.

\section{RESULTS}

\section{Preoperative data and operative details}

Seventy-three eligible patients who underwent 2-stage RPC for UC by 6 staff surgeons were identified. Patient demographic and clinical characteristics are detailed in Table 1. The laparoscopic group consisted of 26 patients (36\%), who had a significantly lower mean BMI than the 47 patients in the open RPC group. There was no significant difference between the 2 groups in terms of smoking prevalence, indications for surgery, preoperative medical treatments, preoperative hemoglobin, and albumin levels, nor the rate of preoperative transfusion.

The laparoscopic group had lower mean values of intraoperative

Table 1. Demographics and preoperative data

\begin{tabular}{|c|c|c|c|c|}
\hline Variable & Total $(n=73)$ & Open $(n=47)$ & Laparoscopy $(n=26)$ & P-value \\
\hline Age at operation (yr) & $43.9 \pm 13.5$ & $43.7 \pm 13.1$ & $44.1 \pm 13.9$ & 0.902 \\
\hline Male sex & $28(39)$ & $17(36)$ & $9(35)$ & 0.894 \\
\hline Body mass index $\left(\mathrm{kg} / \mathrm{m}^{2}\right)$ & $20.1 \pm 3.1$ & $21.1 \pm 3.6$ & $19.0 \pm 2.4$ & 0.025 \\
\hline ASA PS classification & & & & 0.294 \\
\hline I & $9(12)$ & $4(9)$ & $5(19)$ & \\
\hline$\|$ & $57(78)$ & $38(81)$ & $19(73)$ & \\
\hline III & $4(6)$ & $2(4)$ & $2(8)$ & \\
\hline IV & $3(4)$ & $3(6)$ & $0(0)$ & \\
\hline Smoking history & & & & 0.318 \\
\hline Never & $42(58)$ & $30(64)$ & $12(46)$ & \\
\hline Current smoker & $10(14)$ & $5(11)$ & $5(19)$ & \\
\hline Ex-smoker & $21(29)$ & $12(26)$ & $9(35)$ & \\
\hline Previous abdominal operation & $5(7)$ & $5(11)$ & $0(0)$ & 0.085 \\
\hline Duration of disease (mo) & $75.7 \pm 82.6$ & $84.1 \pm 73.8$ & $67.3 \pm 93.6$ & 0.402 \\
\hline \multicolumn{5}{|l|}{ Preoperative medical treatments } \\
\hline Steroid & $57(78)$ & $36(77)$ & $21(81)$ & 0.680 \\
\hline Anti-inflammatory agent & $57(78)$ & $35(75)$ & $22(84)$ & 0.262 \\
\hline Immunomodulator & $34(47)$ & $18(38)$ & $16(62)$ & 0.057 \\
\hline Biologic agent & $20(27)$ & $12(26)$ & $8(31)$ & 0.631 \\
\hline \multicolumn{5}{|l|}{ Indications for operation } \\
\hline Medical intractability & $54(74)$ & $35(75)$ & $19(73)$ & 0.897 \\
\hline Malignancy or dysplasia & $19(26)$ & $12(25)$ & $7(26.9)$ & 0.897 \\
\hline Preoperative hemoglobin $(\mathrm{g} / \mathrm{dL})$ & $11.1 \pm 1.5$ & $11.3 \pm 1.7$ & $10.8 \pm 1.2$ & 0.169 \\
\hline Preoperative albumin (g/dL) & $3.0 \pm 0.5$ & $3.1 \pm 0.5$ & $2.9 \pm 0.5$ & 0.074 \\
\hline Preoperative transfusion & $29(40)$ & $17(36)$ & $12(46)$ & 0.404 \\
\hline
\end{tabular}

Values are presented as mean \pm standard deviation or number (\%).

ASA PS, American Society of Anesthesiologists physical status. 
Table 2. Intraoperative and postoperative results

\begin{tabular}{|c|c|c|c|c|}
\hline Variable & $\begin{array}{c}\text { Total } \\
(n=73)\end{array}$ & $\begin{array}{c}\text { Open } \\
(n=47)\end{array}$ & $\begin{array}{l}\text { Laparoscopy } \\
(\mathrm{n}=26)\end{array}$ & P-value \\
\hline \multicolumn{5}{|l|}{ Intraoperative } \\
\hline $\begin{array}{l}\text { Operative time } \\
\text { (min) }\end{array}$ & $225.6 \pm 45.2$ & $221.8 \pm 41.3$ & $233.9 \pm 54.8$ & 0.288 \\
\hline $\mathrm{EBL}(\mathrm{mL})$ & $275.5 \pm 202.1$ & $345.6 \pm 376.5$ & $165.5 \pm 126.3$ & 0.004 \\
\hline $\begin{array}{l}\text { Anastomosis, } \\
\text { hand-sewn }\end{array}$ & $10(14)$ & $7(15)$ & $3(12)$ & 0.690 \\
\hline \multicolumn{5}{|l|}{ Postoperative } \\
\hline $\begin{array}{l}\text { Days to 1st } \\
\text { passing of } f \\
\text { latus }\end{array}$ & $1.6 \pm 0.4$ & $1.7 \pm 0.6$ & $1.3 \pm 0.5$ & 0.004 \\
\hline \multicolumn{5}{|l|}{ NRS pain score } \\
\hline $\begin{array}{l}\text { Postoperative } \\
\text { day } 1\end{array}$ & $5.4 \pm 2.2$ & $5.8 \pm 2.3$ & $4.8 \pm 2.1$ & 0.029 \\
\hline $\begin{array}{l}\text { Postoperative } \\
\text { day } 7\end{array}$ & $2.6 \pm 2.1$ & $3.1 \pm 2.3$ & $1.8 \pm 2.0$ & 0.027 \\
\hline $\begin{array}{l}\text { Hospital stay } \\
\text { (day) }\end{array}$ & $11.7 \pm 5.0$ & $12.9 \pm 7.0$ & $10.0 \pm 6.0$ & 0.077 \\
\hline Reoperation & $3(4)$ & $2(4)$ & $1(3)$ & 0.933 \\
\hline Readmission & $13(18)$ & $9(19)$ & $4(15)$ & 0.687 \\
\hline Transfusion & $19(26)$ & $14(30)$ & $5(19)$ & 0.325 \\
\hline
\end{tabular}

Values are presented as mean \pm standard deviation or number (\%).

EBL, estimated blood loss; NRS, numeric pain rating scale. blood loss $(\mathrm{P}=0.004)$, time to recovery of bowel function $(\mathrm{P}=$ $0.004)$, and self-reported pain ratings on the first and 7th postoperative days $(\mathrm{P}=0.029$ and $\mathrm{P}=0.027$, respectively) compared to open group (Table 2). There were no conversions of laparoscopy to laparotomy, and there was no significant between-group difference in the mean number of additional opioid doses required during admission.

\section{Postoperative complications}

Table 3 summarizes and compares overall morbidity in the 2 groups. There were no deaths, and the overall rate of complication was $43.8 \%$, with no significant difference in complication rate between the groups. Two patients each had 2 concurrent morbidi-

Table 3. Postoperative complications

\begin{tabular}{lcccc}
\hline Variable & $\begin{array}{c}\text { Total } \\
(\mathrm{n}=73)\end{array}$ & $\begin{array}{c}\text { Open } \\
(\mathrm{n}=47)\end{array}$ & $\begin{array}{c}\text { Laparoscopy } \\
(\mathrm{n}=26)\end{array}$ & P-value \\
\hline Overall complications & $32(44)$ & $24(51)$ & $8(31)$ & 0.094 \\
lleus & $15(21)$ & $13(28)$ & $2(8)$ & 0.043 \\
Small bowel obstruction & $7(10)$ & $3(6)$ & $4(15)$ & 0.211 \\
Septic complication & $5(7)$ & $4(9)$ & $1(4)$ & 0.450 \\
Wound complication & $4(5)$ & $3(6)$ & $1(4)$ & 0.648 \\
Others & $3(4)$ & $2(4)$ & $1(4)$ & 0.933 \\
\hline
\end{tabular}

Values are presented as number (\%).

The number of patients with $\geq 2$ complications: open 1, laparoscopy 1 .

Table 4. Univariate and multivariate analyses for postoperative complications

\begin{tabular}{|c|c|c|c|c|}
\hline \multirow{2}{*}{ Variable } & \multicolumn{2}{|c|}{ Univariate analysis } & \multicolumn{2}{|c|}{ Multivariate analysis } \\
\hline & OR $(95 \% \mathrm{Cl})$ & P-value & OR $(95 \% \mathrm{Cl})$ & P-value \\
\hline Age $>40 \mathrm{yr}$ & $1.2(0.5-3.1)$ & 0.731 & & \\
\hline Male sex & $1.8(0.7-4.9)$ & 0.240 & & \\
\hline Body mass index $>25 \mathrm{~kg} / \mathrm{m}^{2}$ & $1.4(0.5-4.1)$ & 0.544 & & \\
\hline \multicolumn{5}{|l|}{ Smoking history } \\
\hline Never & 1 & - & 1 & - \\
\hline Current smoker & $20.1(2.3-175.3)$ & 0.007 & $44.4(3.8-523.8)$ & 0.003 \\
\hline Ex-smoker & $2.0(0.7-6.0)$ & 0.198 & & \\
\hline Preoperative steroid use & $2.0(0.6-6.4)$ & 0.256 & & \\
\hline Preoperative biologics use & $0.6(0.2-1.8)$ & 0.352 & & \\
\hline Preoperative hemoglobin & $0.9(0.7-1.2)$ & 0.715 & & \\
\hline Preoperative albumin & $1.0(0.4-2.2)$ & 0.966 & & \\
\hline Preoperative transfusion & $0.7(0.3-1.7)$ & 0.410 & & \\
\hline Operative approach, open & $2.4(0.9-6.5)$ & 0.098 & $5.4(1.4-20.5)$ & 0.014 \\
\hline Estimated blood loss > $300 \mathrm{~mL}$ & $0.9(0.3-2.6)$ & 0.801 & & \\
\hline Operative time $>240 \mathrm{~min}$ & $0.3(0.1-0.9)$ & 0.021 & $0.5(0.1-2.0)$ & 0.313 \\
\hline Anastomosis method, hand-sewn & $0.1(0.01-1.0)$ & 0.046 & $0.1(0.01-1.1)$ & 0.056 \\
\hline Postoperative transfusion & $2.9(1.0-8.6)$ & 0.053 & $1.8(0.5-6.5)$ & 0.397 \\
\hline
\end{tabular}

$\mathrm{OR}$, odds ratio; $\mathrm{Cl}$, confidence interval. 
ties. Postoperative ileus was more frequent in the open group (27.7\% vs. $7.7 \%, \mathrm{P}=0.043)$. Seventy percent of complications $(\mathrm{n}=$ 24) were CDC grade I or II, and there was no significant difference in the rates of all CDC grades between the 2 groups. In the multivariate analysis, current smokers $(\mathrm{OR}, 44.4 ; \mathrm{P}=0.003)$ and open approach $(\mathrm{OR}, 5.4 ; \mathrm{P}=0.014)$ were independent risk factors for postoperative complications after RPC (Table 4).

\section{DISCUSSION}

We compared the short-term postoperative outcomes of laparoscopic vs. open RPC for UC and demonstrated that the benefits of laparoscopic RPC include reduced pain and faster recovery of bowel function. Additionally, although preoperative mean BMI, hemoglobin, and albumin were lower in the laparoscopic group, laparoscopic RPC was associated with a lower postoperative complication rate than open RPC; that this difference was not statistically significant might have resulted from the small sample size. Several studies have reported similar advantages of laparoscopic RPC, specifically the reduction in both postoperative pain and postoperative analgesia requirements $[11,12]$. Other studies showed that hospital stay duration and time to tolerability of solid food consumption were shorter with the laparoscopic approach [13]. Other authors demonstrated that laparoscopic RPC provided patients cosmetic advantages and improved quality of life scores [14].

Early complications after IPAA include pouch bleeding, leakage, and pelvic sepsis [15]. Pelvic sepsis is a relatively common and serious complication ( $5 \%-10 \%$ of cases) of IPAA, and it has been identified as a risk factor for long-term pouch failure $[5,15]$. Wound infection, small bowel obstruction, and postoperative ileus have also been identified as common complications, occurring in $8 \%-18 \%$ of cases $[5,13]$. UC patients who are deemed appropriate candidates for RPC are often undernourished and immunocompromised. These patients frequently have a bleeding tendency, and their bowels are often found to be edematous and friable [6]. This unfavorable preoperative status might explain the high rates (up to 35\%) of early complications after IPAA [16].

Several mechanisms of postoperative ileus have been proposed in previous studies [17]. Bowel manipulation can lead to traumatic injury, bowel adhesions, and slower blood flow to the mesentery and bowel wall $[18,19]$. Previous studies demonstrated that intraperitoneal procedures in laparoscopic surgery are performed with relatively minimal manipulation compared to open surgery $[18,20]$; the lower incidence of postoperative ileus in the laparoscopic group of this study may reflect this. Another possible cause for the more frequent ileus in the open group may be the higher postoperative pain intensity reported after the open approach, which may increase postoperative opioid use [17]. However, when we examined the use of opioids in our data, there were no differences in the type and dose of administration of opioids between the 2 groups, and we could not find any association be- tween opioid use and ileus.

Generally, pelvic complications after RPC can be induced by pelvic sepsis, which can be caused by anastomotic dehiscence and by infected pelvic hematomas [5]. Allogenic blood transfusion may trigger deleterious immunomodulatory effects that increase the risk of bacterial infection [21]. According to previous studies, the laparoscopic approach is associated with a significantly lower rate of intraoperative blood loss and less blood transfusion [5, 22]. In our study, postoperative transfusion was required more frequently in the open group than in the laparoscopic group, but this difference was not statistically significant.

In this study, smoking was one of the independent risk factors for postoperative complications. Previous studies have demonstrated that patients who smoked preoperatively had a higher risk of experiencing general morbidity, including wound complications, general infections, and pulmonary complication after an operation $[23,24]$. Several mechanisms have been suggested to explain the effects of smoking on postoperative morbidity [25]. Tissue hypoxia, which causes peripheral ischemia, results from the adrenergic effects of nicotine and peripheral vasoconstriction. Degradation of immune function may increase the risk of postoperative infection. Mature collagen fibers are less abundant in smokers, and this can impair the postoperative wound healing process.

Previous studies showed that there was no distinct relationship between anastomosis method and complications and, moreover, other authors proved that stapled anastomosis is better than handsewn anastomosis method for IPAA $[26,27]$. In this study, however, hand-sewn anastomosis method was a marginally meaningful factor of fewer complications (Table 4). In our data, handsewn anastomosis was performed to only 10 patients and 9 of them underwent RPC for malignancy or dysplasia in rectum or colon. Colonic inflammation of patients who underwent RPC for malignancy or dysplasia is typically better than that of the patient who underwent RPC for medical intractability in their acute phase of the disease, because the neoplastic process occurs after a long duration of disease of more than 10 years despite excellent control of inflammatory symptoms [28]. In this reason, it might not be sufficient to conclude that the hand-sewn anastomosis was related with fewer complications in our study.

Longer operative time has been cited as a major limitation of laparoscopic RPC $[11,13]$. It has been shown that longer operative time could increase postoperative morbidity [17]. However, in our study, the mean operative time for the laparoscopic group was not significantly different from that of the open group. As the uptake of laparoscopic surgery for colorectal cancer and inflammatory bowel disease continues to increase, surgeons will become more proficient at laparoscopic RPC, improving operative times and minimizing complications.

The present study had several limitations that were inherent to its retrospective design and the small volume of cases. First, although there is no significant difference in demographic charac- 
teristics between the 2 groups, it is possible that the heterogeneity of them still exist. In the open group, 5 patients who had undergone abdominal surgeries before RPC were included, but in the laparoscopic group, no patient had a history of abdominal surgery before RPC. These patients in the open group might affect the rate of operative and postoperative outcomes such as ileus, EBL or operative time. Additionally, lower BMI of laparoscopic group might be the result of the selection bias which came from the surgeons' preference to each approach. Second, we included only elective 2-stage RPCs in the open and laparoscopic groups and excluded all emergent cases, such as toxic megacolon, bowel ischemia, bleeding or perforation, and fulminant colitis to minimize the differences between the 2 groups. Thus, our results are not generalizable and do not reflect the outcomes of all types of RPC cases. Third, a precise definition of "medical intractability" was lacking, and there was uncertainty when distinguishing several medically intractable cases from severe or fulminant colitis. Finally, the overall morbidity rate was higher in the open group, but the between-group difference was not statistically significant; the lack of statistical significance might have resulted from the small number of patients, as previously mentioned.

In conclusion, laparoscopic RPC for UC might be an acceptable approach in selective cases in terms of less pain and faster recovery of bowel function.

\section{CONFLICT OF INTEREST}

No potential conflict of interest relevant to this article was reported.

\section{REFERENCES}

1. Cottone M, Scimeca D, Mocciaro F, Civitavecchia G, Perricone G, Orlando A. Clinical course of ulcerative colitis. Dig Liver Dis 2008;40 Suppl 2:S247-52.

2. Eaden JA, Abrams KR, Mayberry JF. The risk of colorectal cancer in ulcerative colitis: a meta-analysis. Gut 2001;48:526-35.

3. Parks AG, Nicholls RJ. Proctocolectomy without ileostomy for ulcerative colitis. Br Med J 1978;2:85-8.

4. Cho W, Cho YB, Kim JY, Chang DK, Kim YH, Kim HC, et al. Outcome of total proctocolectomy with ileal pouch-anal anastomosis for ulcerative colitis. J Korean Surg Soc 2012;83:135-40.

5. Fleming FJ, Francone TD, Kim MJ, Gunzler D, Messing S, Monson JR. A laparoscopic approach does reduce short-term complications in patients undergoing ileal pouch-anal anastomosis. Dis Colon Rectum 2011;54:176-82.

6. Kawamura J, Hasegawa S, Kawada K, Yamaguchi T, Nagayama S, Matsusue R, et al. Feasibility and safety of laparoscopic total proctocolectomy with ileal pouch-anal anastomosis for severe ulcerative colitis. Asian J Endosc Surg 2013;6:271-8.

7. Yang SK, Hong WS, Min YI, Kim HY, Yoo JY, Rhee PL, et al. Incidence and prevalence of ulcerative colitis in the Songpa-Kang- dong District, Seoul, Korea, 1986-1997. J Gastroenterol Hepatol 2000;15:1037-42.

8. Dindo D, Demartines N, Clavien PA. Classification of surgical complications: a new proposal with evaluation in a cohort of 6336 patients and results of a survey. Ann Surg 2004;240:205-13.

9. Gu J, Stocchi L, Remzi F, Kiran RP. Factors associated with postoperative morbidity, reoperation and readmission rates after laparoscopic total abdominal colectomy for ulcerative colitis. Colorectal Dis 2013;15:1123-9.

10. Li Y, Stocchi L, Cherla D, Liu X, Remzi FH. Association of preoperative narcotic use with postoperative complications and prolonged length of hospital stay in patients with crohn disease. JAMA Surg 2016;151:726-34.

11. Chung TP, Fleshman JW, Birnbaum EH, Hunt SR, Dietz DW, Read TE, et al. Laparoscopic vs. open total abdominal colectomy for severe colitis: impact on recovery and subsequent completion restorative proctectomy. Dis Colon Rectum 2009;52:4-10.

12. Hashimoto A, Funayama Y, Naito H, Fukushima K, Shibata C, Naitoh T, et al. Laparascope-assisted versus conventional restorative proctocolectomy with rectal mucosectomy. Surg Today 2001; 31:210-4.

13. Larson DW, Cima RR, Dozois EJ, Davies M, Piotrowicz K, Barnes SA, et al. Safety, feasibility, and short-term outcomes of laparoscopic ileal-pouch-anal anastomosis: a single institutional casematched experience. Ann Surg 2006;243:667-70.

14. Larson DW, Dozois EJ, Piotrowicz K, Cima RR, Wolff BG, YoungFadok TM. Laparoscopic-assisted vs. open ileal pouch-anal anastomosis: functional outcome in a case-matched series. Dis Colon Rectum 2005;48:1845-50.

15. Ryoo SB, Oh HK, Han EC, Ha HK, Moon SH, Choe EK, et al. Complications after ileal pouch-anal anastomosis in Korean patients with ulcerative colitis. World J Gastroenterol 2014;20:748896.

16. Yoon YS, Cho YB, Park KJ, Baik SH, Yoon SN, Ryoo SB, et al. Surgical outcomes of Korean ulcerative colitis patients with and without colitis-associated cancer. World J Gastroenterol 2015;21: 3547-53.

17. Behm B, Stollman N. Postoperative ileus: etiologies and interventions. Clin Gastroenterol Hepatol 2003;1:71-80.

18. Schwarz NT, Beer-Stolz D, Simmons RL, Bauer AJ. Pathogenesis of paralytic ileus: intestinal manipulation opens a transient pathway between the intestinal lumen and the leukocytic infiltrate of the jejunal muscularis. Ann Surg 2002;235:31-40.

19. Ferrari L, Krane MK, Fichera A. Inflammatory bowel disease surgery in the biologic era. World J Gastrointest Surg 2016;8:363-70.

20. Chen HH, Wexner SD, Iroatulam AJ, Pikarsky AJ, Alabaz O, Nogueras JJ, et al. Laparoscopic colectomy compares favorably with colectomy by laparotomy for reduction of postoperative ileus. Dis Colon Rectum 2000;43:61-5.

21. Blumberg N, Zhao H, Wang H, Messing S, Heal JM, Lyman GH. The intention-to-treat principle in clinical trials and meta-analyses of leukoreduced blood transfusions in surgical patients. 
Transfusion 2007;47:573-81.

22. El-Gazzaz GS, Kiran RP, Remzi FH, Hull TL, Geisler DP. Outcomes for case-matched laparoscopically assisted versus open restorative proctocolectomy. Br J Surg 2009;96:522-6.

23. Grønkjær M, Eliasen M, Skov-Ettrup LS, Tolstrup JS, Christiansen AH, Mikkelsen SS, et al. Preoperative smoking status and postoperative complications: a systematic review and meta-analysis. Ann Surg 2014;259:52-71.

24. Shen B, Fazio VW, Remzi FH, Brzezinski A, Bennett AE, Lopez R, et al. Risk factors for diseases of ileal pouch-anal anastomosis after restorative proctocolectomy for ulcerative colitis. Clin Gastroenterol Hepatol 2006;4:81-9.

25. Sopori M. Effects of cigarette smoke on the immune system. Nat
Rev Immunol 2002;2:372-7.

26. Konishi T, Ishida H, Ueno H, Kobayashi H, Hinoi T, Inoue $Y$, et al. Postoperative complications after stapled and hand-sewn ileal pouch-anal anastomosis for familial adenomatous polyposis: A multicenter study. Ann Gastroenterol Surg 2017;1:143-9.

27. Lovegrove RE, Constantinides VA, Heriot AG, Athanasiou T, Darzi A, Remzi FH, et al. A comparison of hand-sewn versus stapled ileal pouch anal anastomosis (IPAA) following proctocolectomy: a meta-analysis of 4183 patients. Ann Surg 2006;244:18-26.

28. Sunkara S, Swanson G, Forsyth CB, Keshavarzian A. Chronic inflammation and malignancy in ulcerative colitis. Ulcers 2011; 2011:8. 